\title{
NAÇÃO, NACIONALISMO E DIFERENÇAS DE GÊNERO E RAÇA NA REPÚBLICA DOMINICANA E NO HAITI
}

\author{
Renata de Melo Rosa ${ }^{1}$
}

\section{Resumo:}

O objetivo deste artigo é dialogar com expoentes da literatura clássica sobre a nacionalidade no sentido de entender a força do imaginário coletivo na formação do nacionalismo e das identidades nacionais.

Proponho que as alteridades que se formam no interior desta nação indicam a impossibilidade da mesma ser entendida como uma comunidade de similares, mas sim como um grupo hierarquizado a partir das diferenças de gênero e raça, entre outras.

Palavras-chaves: Nacionalismo; Gênero; Raça;

O objetivo deste artigo é dialogar com expoentes da literatura clássica sobre a nacionalidade no sentido de entender a força do imaginário coletivo na formação do nacionalismo e das identidades nacionais. Ao condicionar o nacionalismo a uma faculdade de invenção de um "nós nacional" que se opõe a uma ou mais alteridades nacionais, esta literatura localiza as raízes do nacionalismo para além das condições concretas que estruturam a existência social das nações. Em concordância com esta perspectiva teórica, pretendo explorar os limites do imaginário dominicano que, ao edificar uma oposição perfeita com a identidade haitiana define, através do horror ao "outro", sua própria identidade. Mas, em discordância com ela, proponho que a existência de um "ser nacional" dominicano pressupõe a construção de alteridades também no âmbito da nação, comprometendo a idéia de que a mesma possa ser pensada como comunidade de similiares. A base de dados de minha pesquisa de campo na República Dominicana ${ }^{2}$ sobre mulheres dominicanas casadas com europeus aponta que elas recebem um tratamento de repulsa por parte de seus compatriotas, que passam a concebê-las como cidadãs de segunda categoria.

\footnotetext{
${ }^{1}$ Doutora em Antropologia da América Latina e Caribe - UnB

${ }^{2}$ Esta pesquisa foi financiada pela CAPES e foi realizada entre os anos de 2001 e 2002.
} 
A partir desta interpretação, proponho que as alteridades que se formam no interior desta nação indicam a impossibilidade da mesma ser entendida como uma comunidade de similares, mas sim como um grupo hierarquizado a partir das diferenças de gênero e raça, entre outras.

Em Nação e Consciência Nacional, Benedict Anderson examina o nacionalismo como fenômeno composto por ordenamentos culturais e conjuntos de relações que podem sofrer alterações históricas a ponto de redefinir as construções de alteridades nacionais e até mesmo redimensionar a própria motivação de criação de um "outro". Estas idéias são promissoras e estimulam a crítica que tem a expectativa de contribuir com um mundo mais igualitário. $\mathrm{O}$ autor reconhece que tanto a cultura como a história imprimem marcas diferenciadas aos distintos projetos nacionais e nos proporcionam pensar a nacionalidade e o nacionalismo como fatos culturais que por terem adquirido profundidade histórica são considerados autênticos e retiram sua mais sincera justificação das emoções que despertam:

\footnotetext{
"Parto de que a nacionalidade, ou como talvez se prefira dizer, devido às múltiplas significações dessa palavra, nation-ness, bem como o nacionalismo, são artefatos culturais de um tipo peculiar. Para compreendê-los adequadamente é preciso que consideremos com cuidado como se tornaram entidades históricas, de que modo seus significados se alteraram no correr do tempo, e por que, hoje em dia, inspiram uma legitimidade emocional tão profunda" ${ }^{3}$.
}

A definição de nação de Anderson envolve as noções de limite e soberania, diretamente ligadas à construção do "outro", sempre situado para além da fronteira geopolítica. A partir das observações do autor, é possível perceber como a construção da

\footnotetext{
${ }^{3}$ Ver Benedict Anderson, Nação e Consciência Nacional, São Paulo: Ática, 1991, p. 12.
} 
nação possui a peculiaridade de estar desvinculada do dado empírico e encontra no imaginário seu principal veículo de elaboração. Segundo Anderson, a nação é, antes de tudo, uma comunidade política imaginada como entidade territorial limitada e soberana:

"Ela é imaginada porque nem mesmo os membros das menores nações jamais conhecerão a maioria de seus compatriotas (...) é imaginada como limitada, porque até mesmo a maior delas, que abarca talvez um bilhão de seres humanos, possui fronteiras finitas, ainda que elásticas, para além das quais encontram-se outras nações. É imaginada como soberana, porque (...) as nações sonham em ser livres (...) O penhor e o símbolo dessa liberdade é o Estado soberano ${ }^{4 \%}$.

Hobsbawn, ${ }^{5}$ tal como Anderson, nota a força do imaginário nos processos de construção das nações, argumentando que isto ocorre em virtude do passado se apresentar como um dos elementos constitutivos da nação; e de seus fatos serem convenientemente selecionados para fundamentar os interesses dos nacionalismos. Considerando que a nação se constrói de acordo com suas aspirações temporais por meio do manejo cuidadoso da história, o autor entende que a narrativa da nação pode ser comparada à narrativa mítica, na qual, as contradições desaparecem ou estão submersas na constituição da própria narrativa:

“O que faz uma nação é o passado, o que justifica uma nação em oposição a outras é o passado, e os historiadores são as pessoas que o produzem (...) Infelizmente, a história que os nacionalistas querem não é a história que os historiadores profissionais, até mesmo os que estão ideologicamente comprometidos, têm que fornecer. Ela é uma mitologia retrospectiva. Deixem-me repetir mais uma vez as palavras de Ernest Renan

\footnotetext{
${ }^{4}$ Idem, p. 14.

3 Ver Eric Hobsbawn, "Etnia e nacionalismo na Europa de hoje" In: BALAKRISHNAN, Gopal (org.). Um Mapa da Questão Nacional, op. cit.
} 
em sua famosa conferência intitulada “O que é uma nação?”, de 1882; “O esquecimento da história, ou mesmo o erro histórico [l'érreur historique], é um fator essencial na formação de uma nação, razão por que o avanço dos estudos históricos é sempre perigoso para a nacionalidade ${ }^{6 \%}$.

Hobsbawn (2000:272-3) também destaca que embora os nacionalismos sejam claramente fenômenos de natureza política, sempre partem do pressuposto de que a nação é uma entidade naturalmente dada no âmbito de um território delimitado e preferivelmente contínuo.

Para os propósitos deste artigo, a idéia mais importante desses autores é que o imaginário intervém tanto na elaboração de um "nós nacional" como na determinação das alteridades nacionais. De acordo com a linha de argumentação dos dois autores, este movimento é primordialmente uma faculdade do imaginário e tanto o horror ao "outro" como o desejo de sê-lo são processos que se elaboram de forma desassociada das condições concretas que estruturam a existência social da nação e do "outro" nacional. Um exemplo da criação imaginária do "outro" é a xenofobia, à qual Hobsbawn se refere como o veículo de recomposição dos esgarçados laços sociais. O autor enfatiza que, a despeito da existência de fatores sociais e políticos que possam desencadeá-la, a xenofobia pode ser acionada sem que exista qualquer contexto que a fomente, pois fundamenta-se na preservação de um estado de coisas, imaginado como correto que encontra-se ameaçado pela presença dos "outros".

“A xenofobia nacional que se matiza de racismo é quase universal. E levanta um problema que não sei solucionar. Que é, exatamente, que se defende contra "os outros", identificados com os imigrantes estrangeiros? Quem constitui o "nós" é uma questão

\footnotetext{
${ }^{6}$ Idem, pp.271-2.
} 
menos problemática, pois a definição costuma ser feita em termos dos Estados existentes. "Nós" somos franceses, ou suecos, ou alemães, ou até membros de subunidades politicamente definidas, como os lombardos, mas distintos dos "eles" invasores, por sermos os "verdadeiros" franceses, alemães ou britânicos, como (usualmente) definidos pela suposta descendência ou residência de longa data. Quem são "eles" também não é difícil. "Eles" são reconhecíveis como "não nós", em geral pela cor ou por outros estigmas físicos, ou pela língua. Quando esses sinais não são evidentes, podem-se fazer discriminações mais sutis: quando se recusam a entender os anglófonos que falam com sotaque canadense, os naturais de Quebec respondem aos anglófonos que falam com entonação britânica ou norte-americana, assim como os flandrenses que afirmam não entender o francês falado com sotaque belga compreendem o francês da França (...) Na verdade, como sugere a expansão global dos restaurantes indianos e chineses, a xenofobia se volta contra as pessoas estrangeiras e não contra as importações culturais estrangeiras.

(...)

O que se está defendendo não é simplesmente a posição de indivíduos do grupo A contra a ameaça de forasteiros (...) Em certo sentido, o que se defende é a idéia do "nós" como um corpo de pessoas unidas por um número incontável de coisas que "temos" em comum - um "estilo de vida", no sentido mais amplo, um território comum de existência em que vivemos, e cuja paisagem nos é familiar e reconhecível. É a existência disso que fica ameaçada com a entrada do que vem de fora ${ }^{7 \%}$.

Hobsbawn conclui sua análise destacando que a xenofobia está ligada a todo e qualquer projeto nacionalista, a partir do princípio de que a definição de nação supõe um "nós", que é constituído a partir da existência dos "outros”.

\footnotetext{
${ }^{7}$ Ver Eric Hobsbawn, op. cit., p. 278-280.
} 
É possível propor, entretanto, uma interpretação da xenofobia não apenas a partir do significado imediato de horror ao "outro", mas também a partir dos interstícios identitários que a edificação de qualquer identidade nacional inevitavelmente produz.

$\mathrm{Na}$ nação dominicana, a xenofobia que adquire a forma de antihaitanismo, consolida-se a partir da elaboração de uma alteridade absoluta, elementar, uma oposição binária equivalente às existentes entre homens e mulheres; e negros e brancos. Sendo assim, a identidade dominicana relaciona-se com a haitiana a partir da edificação dos limites geopolíticos, raciais e nacionais. E. por constituírem alteridades totais, os haitianos acabam definindo o povo dominicano.

É possível pensar a relação entre dominicanos e haitianos a partir do modelo explicativo sugerido por Frantz Fanon ${ }^{8}$, a partir do princípio de que nem o branco nem o negro existem como unidades autônomas, mas como categorias criadas em um determinado contexto histórico. De acordo com Fanon, a contrastividade excessiva oculta o princípio de transitabilidade existente na construção de qualquer alteridade. Assim, dominicanos e haitianos podem ser pensados como identidades que, apesar de concebidas de forma dicotômica, especialmente no pensamento social dominicano, são transitáveis. O lugar de conexão entre identidades polares pode ser visto a partir de um entre-lugar, que por não ser sedimentado, mistura e confunde os elementos fixos que estruturam esta dicotomia. De acordo com Bhabha ${ }^{9}$, o processo de demarcação das fronteiras e de dicotomias cria o "outro", na medida em que reconhece a não contigüidade. Assim, é possível perceber que, se a construção da alteridade anuncia o "outro", os conteúdos das oposições e das

\footnotetext{
${ }^{8}$ Ver Frantz Fanon. Pele Negra, Máscaras Brancas, op. cit.

${ }^{9}$ Ver Homi Bhabha, op. cit.
} 
dicotomias não podem ser vistos como campos autônomos, mas como fenômenos inscritos em uma mesma lógica que, no limite, indicam transitabilidade.

Para Bhabha, o entre-lugar se revela, especialmente no lugar da memória e do imaginário. Sendo assim, é possível realizar uma leitura do exterior para a descoberta da subjetividade, da intersubjetividade e do imaginário, pois tais campos se fundem ao coletivo, e, por vezes, se manifestam publicamente. Bhabha indica a fragilidade das lógicas binárias, pois acredita na existência de uma passagem intersticial entre identidades fixas que desafia a dinâmica da construção das identidades polares.

De acordo com esta linha de raciocínio, é possível supor que o entre-lugar da identidade dominicana é um espaço aberto e ameaçador porque abre a possibilidade de mistura dos signos que estruturam a dicotomia dominicano/haitiano. Partindo do princípio enunciado por Fanon e corroborado por Bhabha, a "projeção de alteridade" entre dominicanos e haitianos conduz à reflexão de que o haitiano é, no entre-lugar desta alteridade, contíguo ao dominicano. Dessa maneira, os haitianos participam ativamente do "nós" dominicano, na medida em que as oposições utilizadas na construção das duas identidades também servem para desconstruí-las, o que nos autoriza a refletir que o haitiano está, de uma maneira negada, no centro da formação da identidade dominicana. Apesar das inúmeras fronteiras construídas para fixar as duas identidades, é possível supor a existência de uma passagem que não apenas permite transitar de uma identidade a outra, mas também reconhecer a contigüidade. Assim, é perfeitamente possível supor que o "nós" dominicano não pode ser imaginado sem que o haitiano também se faça presente. 
Sob esta perspectiva, o entre-lugar do nacionalismo dominicano ${ }^{10}$ revela a possibilidade de ofuscar o alinhamento das dicotomias, a partir do princípio de que o interstício da identidade dominicana abriga a dissidência e a dissonância, tal como informaram as interlocutoras quando diziam que o dominicano também é negro.

Sustento os aspectos que, na abordagem clássica sobre o nacionalismo, apontam para a sua qualidade política e para a delimitação de fronteiras geopolíticas que definem a construção de alteridades nacionais, as quais motivam os mais diversos tipos de xenofobias. No entanto, apesar de Anderson e Hobsbawn não afirmarem propriamente que a nação é constituída por um corpo homogêneo de indivíduos, acredito que no corpo de suas análises existe um conteúdo a-crítico acerca desta noção. Os dados etnográficos de minha pesquisa confirmam um obstáculo metodológico para pensar que o projeto nacionalista se resume em construir um "outro" fora dos limites da nação porque o nacionalismo também pressupõe a existência de "outros" dentro da nação. No que concerne à construção de alteridades nos processos nacionais, Hobsbawn e Anderson se limitam a apontar as externas, sem considerar as internas. Ademais, parecem aceitar a-criticamente a existência do nation-ness. Nesse sentido, a aceitação da consciência nacional como um dado objetivo pode ser impeditivo à percepção de que a construção da alteridade percorre uma via de mão dupla. As alteridades não estão somente fora da fronteira nacional, em oposição a um "nós" homogêneo, mas também estão presentes na estruturação do corpo da nação.

\footnotetext{
${ }^{10}$ O período de Restauración (1844-65) é considerado o primeiro movimento nacionalista de expulsão definitiva da ocupação haitiana. Após este período, o nacionalismo recrudesce para ganhar novo fôlego na era Trujillo (1930-61), na qual, a matança de cinco mil haitianos na fronteira dominico-haitiana é o ponto mais evidente de sua política xenófoba. Após a era Trujillo, o nacionalismo dominicano surge de tempos em tempos, a partir do velho conhecido slogan de um plano de anexação da ilha, por parte do governo haitiano. Nas eleições presidenciais de 1996, o então candidato à Presidência Peña Gómez foi acusado de ter um plano de unificação da ilha, pelo fato de declarar sua descendência haitiana e manter vínculos com este país.
} 
Isto pode ser evidenciado pelos papéis de gênero inscritos na formação da nação que implicam prerrogativas diferentes, direitos diferenciados que, se não estão inscritos formalmente, expressam-se nos hábitos e na própria tradição. A referência a uma "consciência étnica" nacional, ou a um nation-ness explicitados por Hobsbawn e Anderson, respectivamente, capazes de delimitar as fronteiras entre o "nós" nacional e os "outros" é o ponto em torno do qual a abordagem clássica apresenta limites de interpretação à base de dados etnográficos de minha pesquisa. É possível que existam fronteiras que separem os indivíduos dentro da nação, através do gênero, da raça, ou de determinadas posturas frente ao poder.

Entretanto, isso não equivale a dizer que o processo de mão de dupla de construção de alteridades seja uniforme. Existem mecanismos distintos de definição de alteridades internas à nação e outros que irão definir as fronteiras dos "outros" fora da nação. Vale dizer que o processo que identifica o "outro" interno à nação pode ser distinto daquele que se dedica à construção do "outro" fora dos limites da nação. O trecho a seguir demonstra as limitações que a fidelidade intelectual à leitura de Anderson pode conduzir:

\footnotetext{
“A nação é imaginada como comunidade porque, sem considerar a desigualdade e exploração que atualmente prevalecem em todas elas, a nação é sempre concebida como um companheirismo profundo e horizontal. Em última análise, essa fraternidade é que torna possível, no correr dos últimos dois séculos, que tantos milhões de pessoas, não só matem, mas morram voluntariamente por imaginações tão limitadas ${ }^{11}$.
}

\footnotetext{
${ }^{11}$ Ver Benedict Anderson, op. cit., p.16.
} 
Talvez minha crítica incida no fato de Hobsbawn não ter examinado que as alteridades nacionais estão firmadas no trânsito com os "outros" e que as nações, ao escolherem estas alteridades, também transitam por elas. Com relação às proposições de Anderson, a aceitação da existência de um “companheirismo profundo e horizontal”, revela a desconsideração da idéia de que, subjacente ao próprio corpo da nação, existem alteridades que se constituem, especialmente em relação ao centro do poder. Refiro-me especificamente às mulheres e aos grupos raciais minoritários.

Parto então da perspectiva de que a nação não é um todo homogêneo organizado em torno de valores comuns e composto por uma "população homogênea", mas que, de modo diverso, é capaz de produzir alteridades internas e sustentar uma atititude xenofóbica perante aos "outros" contíguos à nação, e dessa maneira, gostaria de explorar os limites que embasam a formação dessas alteridades internas à nação.

Os referenciais empíricos de minha pesquisa de campo corroboram para a proposição de que o nacionalismo se nutre tanto por meio da construção de alteridades nacionais como de alteridades existentes no interior da nação. Edmund, alemão de Munich, casado com Miguelina (dominicana de Monte Cristi), constitui um exemplo desta interpretação, pois não compartilha com seus compatriotas um "companheirismo profundo e horizontal" e se recusa a manter contato com os alemães que residem em Juan Dolio. Isto porque, para ele, as hierarquias que estruturam a nação alemã e constroem os "outros" internos fazem parte de sua visão da nação alemã e de sua identidade nacional que deve primar pela obrigação de ser um "bom alemão". A identificação dos alemães orientais como um "outro" profundamente negativo ("maus alemães”) está expressa em suas atitudes e discursos. Ao ver as tentativas frustradas de seus compatriotas em cumprimentá-lo, perguntei-lhe, em uma ocasião: 
“-¿Por qué tú no habla con ellos?

Ah, sí. Tú estas hablando de Rico y el amigo. Bueno, esos muchachos son de Alemania excomunista. Vivian en un barrio de la periferia de Berlín. Ellos son amigos desde niños y vinieron para casarse con las hermanas, las muchachas de Pepe. Ellos tienen como muchos tatuajes en el cuerpo, no me gusta eso... un comportamiento extraño. Pero yo no tengo que ver con sus comportamientos y tampoco estoy obligado a hablar con ellos.

-¿Hay muchos prejuicios en contra los alemanes orientales?

Lo que pasa es que hay una relación que personalmente no me gusta. Pero mismo después de la separación de Berlín, mismo después del muro, los comunistas siguieron llamando a los alemanes occidentales a ocupar los altos rangos porque ellos no sabían cómo manejar la cosa. Y eso creó un sentimiento hacia los alemanes ex-comunistas. Siempre estamos pensando en enseñarles algo, que ellos todavía necesitan aprender cosas sobre la vida. Esa no es una buena relación. Y esos muchachos son de allá. Huyeron para el Caribe porque quizás querían más libertad... no lo sé, yo no sé mucho de ellos.”

A resposta que a nação dominicana dá às mulheres não-brancas que se relacionam com europeus ou norte-americanos está calcada na reprovação pública à existência desses casais. Nesse sentido, este nacionalismo se fundamenta a partir da atribuição de lugares diferenciados de homens e mulheres e de negros e brancos. Talvez o incômodo que estes casais provocam não constitua uma peculiaridade desta nação, senão a própria expressão do nacionalismo, que concomitantemente à criação das alteridades nacionais também se nutre de alteridades existentes no interior da nação. A história relatada por Miguelina é significativa de sua condição de cidadã de segunda classe:

"Una vez fuimos con el niño en un Hotel de Sosua a buscar un amigo de mi marido. Y él subió y cuando yo iba, el funcionario me dijo: "No, tú no puedes subir". Y mi marido dijo: 
“Es mi esposa y mi hijo.”. Y ellos: “No, todas dicen así. Son putas, todas son.” Era un dominicano negro y él me dijo: “Todas las mujeres negras son iguales”. Y yo le dije: "Mira, señor, yo estoy aquí". Y fuimos hablar con la recepción y ellos dijeron: “Ay, sí, lo que pasa es que aquí en Sosua hay como dos mil putas y todas son iguales. Y yo dije: "Sí, pero seguro tú notas una diferencia porque yo entré con él y él niño". Y él: "Sí, pero es igual. Todas las mujeres negras son así". Y yo dije: "Este es un país negro y mulato y ni todas las mujeres negras y mulatas necesariamente tienen que se casar con hombre alemán sendo una prostituta. También hay mujeres que tienen sentimiento y usted es un dominicano". Entonces yo me siento mal que en mi propio país me traten así. Y así salimos. Pero así me pasó otra vez. A veces, por ejemplo, estábamos caminando y la gente me decía: ¡Puta!’

Toda esta reflexão nos remete ao tratamento diferenciado das mulheres e dos grupos raciais minoritários nos processos de formação nacional e na dinâmica do nacionalismo. Historicamente, tais alteridades denunciaram a fragilidade dos projetos nacionais que, por suporem a contemplação dos valores da igualdade e da liberdade para todos os seus cidadãos, naturalizavam as diferenças de gênero e raciais que transversalizam a estrutura das nações ${ }^{12}$.

Sylvia Walby ${ }^{13}$ faz uma reflexão a respeito do lugar da mulher nos projetos nacionalistas. Para a autora, o nacionalismo é um projeto que afeta homens e mulheres de maneira diferenciada. Ela faz uma crítica ao modo pelo qual as teorias que se ocupam do tema nacional negligenciam o sexo em suas abordagens.

\footnotetext{
12 Isto é particularmente válido para a visão dos movimentos sociais, dentre os quais se destacam o movimento negro, o feminista, de minorias sexuais e raciais, etc.

${ }^{13}$ Sylvia Walby, "A Mulher e a Nação", In: BALAKRISHNAN, Gopal (org.). Um Mapa da Questão Nacional, op. cit.
} 


\begin{abstract}
"A literatura sobre as nações e o nacionalismo raramente aborda a questão do sexo, a despeito do interesse geral na participação dos vários grupos sociais nos projetos nacionalistas (...) esse corpus bibliográfico pouco se tem interessado pela integração diferencial de mulheres e homens no projeto nacional. A maioria dos textos sobre o nacionalismo não leva em conta o sexo como uma questão de peso. Raras e, portanto, importantes exceções a essa ausência são Enloe, Jayawardena e Yuval-Davis e Anthias"14.
\end{abstract}

Walby retira parte de sua argumentação das constatações de Yuval-Davis e Anthias $^{15}$ que apontam a inserção diferenciada de homens e mulheres nos projetos nacionais e descrevem cinco formas gerais de participação das mulheres nos processos étnicos e nacionais. São elas: 1) como reprodutoras biológicas de membros de coletividades étnicas; 2) como reprodutoras das fronteiras étnicas dos grupos nacionais; 3) como partícipes centrais na reprodução ideológica da coletividade e como transmissoras de sua cultura; 4) como marcadoras das diferenças étnicas ou nacionais, como foco e símbolo usado nos discursos ideológicos na construção, reprodução e transformação de categorias étnicas ou nacionais; 5) como participantes das lutas militares, políticas, econômicas e nacionais ${ }^{16}$.

Walby sugere uma modificação no modo de interpretação da participação das mulheres no projeto nacional. Sua argumentação principal está baseada no "envolvimento feminino diferenciado" e sua sugestão é pensar os homens e as mulheres não como blocos

\footnotetext{
${ }^{14}$ Cynthia Enloe, Bananas, Beaches and Bases: Making Feminist Sense of International Politics, Londres, 1989; Kumari Jayawardena, Feminism and Nationalism in the Third World, Londres, 1986; Nira Yuval-Davis e Foya Anthias (orgs.), Woman-Nation-State, Londres, 1989, nota da autora, op. cit., p. 249.

${ }^{15}$ Ver Floya Anthias e Nira Yuval-Davis. Racialized Boundaries: race, nation, gender, colour and class and the anti-racist struggle, Londres e Nova York: Routledge, 1992.

${ }^{16}$ Idem, p. 115.
} 
homogêneos, mas subdivididos por interesses distintos e contextuais. Walby discute que mulheres e homens não partilham a mesma identidade grupal, tampouco o mesmo projeto nacional e, por essa razão, mulheres e homens "podem ter compromissos diferentes com diferentes tipos de grupos no nível macrossocial ${ }^{17,}$.

A discussão sugerida por Walby nos remete à reflexão acerca das diversas teorias feministas, cujo foco de análise consiste em demonstrar a impossibilidade de abordagem de conceitos abrangentes como classe, Estado e nação sem que se leve em consideração as diferenças de gênero. Pensar a mulher como a guardiã da nação é algo recorrente nos diversos tipos de nacionalismos. Geralmente, associa-se à função reprodutora e ao útero os elementos que irão reproduzir pessoas e, consequientemente, valores de um determinado ideário nacional ou étnico.

Walby também sugere que os projetos nacionais são, simultaneamente, projetos sexuais. A autora entende que os projetos nacionais das mulheres não são idênticos aos dos homens e que pode haver um entendimento de gênero diferenciado a respeito da definição das fronteiras. Ademais, os interesses femininos e masculinos devem ser contextualizados, pois se modificam ao longo do tempo. Como existe uma disputa entre os vários grupos de poder para a definição do projeto nacional e dos interesses a serem privilegiados, é provável que, pelo fato de as mulheres estarem à margem do poder, suas vozes sejam menos ouvidas que a dos homens. Dessa forma, os papéis de gênero são importantes para a própria definição do projeto nacional. Nessa mesma esteira de pensamento, Walby coloca que "o sexo, a etnia e a classe têm relações diferentes com a nação ${ }^{18 "}$. Isso indica que no jogo de forças de conceituação do projeto nacional, determinados grupos podem não se

\footnotetext{
${ }^{17}$ Silvia Walby, op. cit., p. 257.

${ }^{18}$ Ver Sylvia Walby, op. cit., p. 264.
} 
identificar com o tipo de projeto nacional estabelecido desde o topo do poder. Dessa forma, a relação dinâmica entre o gênero, a raça e o Estado condicionam o tipo de projeto nacional adotado por cada nação.

O reconhecimento dos "envolvimentos diferenciados" de acordo com o gênero frente à nação e o nacionalismo abrange também a discussão acerca dos direitos diferenciados de homens e mulheres, dos acessos diferenciados à cidadania e da maneira diferenciada que os gêneros são percebidos face à idéia de liberdade sexual. Nesse sentido, é possível perceber que a reprovação da união de mulheres com estrangeiros está, ela mesma, no cerne da formação do nacionalismo moderno. Studer ${ }^{19}$, em seu trabalho acerca de cidadania e nacionalidade na Suíça aponta para a desigualdade formal e até mesmo à perda de nacionalidade que as mulheres suíças estavam submetidas, caso se casassem com estrangeiros.

\footnotetext{
"Women and men received unequal treatment firstly in the internal relation of state to citizens, and secondly in the external relation of state to non-nationals. (...) Historical research, and specially research in gender history, has long demonstrated that citizenship is a dynamic concept and that not all citizens enjoyed citizenship rights in equal measure. But as regards nationality, too, in many states an exception existed until well into the twentieth century. Nationality was far from being something whole, indivisible or absolute that could only be lost through voluntary renunciation: if a woman married a foreign national, she was deprived of her own nationality ${ }^{20 \text { ", }}$
}

\footnotetext{
${ }^{19}$ Brigitte Studer. "Citizenship as Contingent National Belonging: Married Women and Foreigners in Twentieth-Century Switzerland”, Gender \& History, Vol. 13 No. 3. Novembro 2001, pp. 622-654.

${ }^{20}$ Idem, p. 623.
} 
A perda da nacionalidade da mulher suíça casada com um estrangeiro vigorou, em termos legais, até 1992, posto que a Suíça não assinou a ratificação da Convenção das Nações Unidas, em 1957, que tinha como um dos objetivos salvaguardar a nacionalidade da mulher, em casos de casamento ou divórcio com estrangeiros. A esse respeito, a autora observa que a hierarquia de direitos entre homens e mulheres, cuja evidência é o controle do acesso à nacionalidade das mulheres casadas com estrangeiros:

\begin{abstract}
"From women who married foreign nationals, one of the most important principles of the modern nation state was violated - the principle that there can be no involuntary loss of nationality. This fact will serve as a magnifying lens to examine the gendered construction of the national. (...) Excluding women who had married foreigners also meant drawing normative boundaries internally. The use of certain 'gender technologies' in the construction of the national, by which knowledge of gender were deployed to regulate the political, served to specify the rights and duties of the Swiss citizen, and specially the female Swiss citizen. They served to delimit the 'imagined political community', as Benedict Anderson has defined the nation, and to determine who was outside $i^{21}$ ".
\end{abstract}

De maneira análoga às observações de Mauss a respeito do lugar da mulher nas sociedades da Polinésia ${ }^{22}$, nas quais, as mulheres possuíam o mesmo status dos estrangeiros, Studer coloca que o lugar da mulher dentro da nação pode ser pensado como análogo ao do estrangeiro, pois ambos são inscritos da nação sob certas prerrogativas e,

\footnotetext{
${ }^{21}$ Idem, p. 624.

${ }^{22}$ Refiro-me ao texto "A Expressão Obrigatória dos Sentimentos, no qual, Mauss (1979) assinala a divisão sexual existente no exercício das funções rituais funerárias australianas. De acordo com a nota 11 presente neste texto, Mauss descreve que "a mulher é um ser minoris resistentiae, encarregada, assim como os estrangeiros, dos ritos dolorosos ( $c f$. Durkheim. Formes élémentaires. p. 572); aliás, ela mesma costuma ser estrangeira, é humilhada com os vexames que outrora o grupo infligia a todos os seus membros”, p. 151.
} 
dessa forma, as mulheres são representadas pelo que Studer chamou de "nacionalidades instáveis".

\begin{abstract}
"Women, too, were part of the Swiss nation, but in contrast to male citizens their membership was a contingent one. If they married a foreigner, they were assumed to have taken up a position outside the community of national solidarity. Gender acted as a marker in the process of setting internal boundaries between 'self' and 'other' that was initiated in Switzerland by the First World War. It provided a symbolic boundary between a nationality that was stable and permanent, thus grounded in loyalty, and one that was inherently unstable. The resultant norm had tangible effects on the agency and actions of citizens, depending on their gender ${ }^{23}$.
\end{abstract}

As reflexões de Studer indicam como a nacionalidade pode ser retirada da mulher, posto que a permanência da mulher na nação depende de um código determinado de conduta que, por ser um valor dominante, é também invisibilizado. Somente quando uma mulher tenta ir contra o que Durkheim chamou de "corrente social" 24 é que se torna evidente o caráter obrigatório de se casar com um nacional. Isso implica concluir que este casamento lhe é exigido e constitui obrigação e condição de acesso à sua nacionalidade. Se quisermos utilizar uma expressão durkheimiana, o casamento de uma mulher com um nacional se configura a partir da definição clássica de fato social. É possível observar, dessa forma, que o foco de motivação que conduz o rechaço ao casal inter-nacional e inter-racial está no próprio policiamento das alteridades internas à nação, dado que a condição de

\footnotetext{
${ }^{23}$ Ver Brigitte Studer, op. cit., pp. 646-7.

${ }^{24}$ Apesar da definição de fato social ser suficientemente conhecida do público leitor de ciências sociais, vale a pena rememorar o que Durkheim observa: "Esses tipos de conduta ou de pensamento não são apenas exteriores ao indivíduo, são também dotados de um poder de imperativo e coercitivo, em virtude do qual se lhe impõem, quer queira, quer não. Não há dúvida de que esta coerção não se faz sentir, ou é muito pouco sentida quando com ela me conformo de bom grado (...). mas não deixa de constituir caráter intrínseco de tais fatos, e a prova é que se afirma desde que tento resistir" In: As Regras do Método Sociológico, São Paulo: Martins, 1975, p.2.
} 
acesso à nacionalidade é subordinada à obediência de certas normas específicas de conduta. Entretanto, gostaria de explorar o modo como a "nacionalidade instável" da mulher se desdobra em nações outrora colonizadas. Penso que nesse tipo de nação, o casamento de uma nacional com um europeu ou norte-americano (ou qualquer estrangeiro que apresente a esteoritipia "loiro de olhos azuis") vai além da perda simbólica ou efetiva da nacionalidade. Parece-me útil dedicar algumas palavras acerca do modo como a memória colonial ratifica a formação de alteridades internas à nação, nas quais estão incluídas as mulheres e os grupos raciais minoritários. Assim, o "fato colonial" é um elemento adicional na estigmatização de cariocas e dominicanas que se casam com estrangeiros loiros de olhos azuis, pois nestes casos, estão ressaltadas não apenas as prerrogativas entre os gêneros, mas também entre as raças que, por engendrarem uma hierarquia, produzem também lugares diferenciados para negros e brancos.

Verena Stolcke ${ }^{25}$ é uma das poucas vozes críticas que se ocupam de problematizar a relação entre gênero, raça e colonialismo nas Américas. A autora indica que tal relação é constitutiva de grande parte dos nacionalismos latino-americanos. Ao retratar a trajetória do nacionalismo mexicano, Stolcke se reporta à história de dona Marina, indígena, amante de Cortez, conquistador espanhol. Malinche é seu pseudônimo e quer dizer a prostituta que se entrega voluntariamente ao conquistador espanhol. Tão forte é esta categoria na memória colonial mexicana que o termo malinchismo é usado para designar os traidores da pátria.

A referência a este imaginário indica que a relação amorosa com o colonizador é sinônimo de antipatriotismo e, possivelmente um forte motivo para a perda de nacionalidade da mulher, ou traduzindo para as palavras de Anderson, para a perda do

\footnotetext{
${ }^{25}$ Ver Verena Stolcke, "Mulheres invadidas: sexo, raça e classe na formação da sociedade colonial”, Caderno de Estudos Afro-Asiáticos, op. cit.
} 
“companheirismo profundo e horizontal”. Stolcke prossegue sua discussão argumentando que não é possível interpretar os excessos sexuais dos colonizadores com as índias e africanas a partir do dado de escassez de mulheres nacionais. A prepotência dos conquistadores consistia em demonstrar domínio do sexo da mulher nativa ou escrava e reforçar a hierarquia sexual, econômica e racial. Stolcke coloca que, de acordo com os informes de Konetzke (1958-1962:148), a escassez de mulheres já não existia desde meados do século XVI, posto que o incentivo às espanholas para habitarem as colônias era uma das principais preocupações da Coroa Espanhola desde o início da colonização ${ }^{26}$.

Octavio $\mathrm{Paz}^{27}$ em $O$ Labirinto da Solidão dedica um capítulo para abordar o significado do termo "Os filhos da Malinche" no México. Paz começa descrevendo a áurea de mistério que ronda os mexicanos, os amarelos e os negros para, em seguida, retratar o enigma da Mulher. $\mathrm{O}$ autor descreve a mulher como uma alteridade enigmática, ininteligível, rodeada de mistérios, um ser que "à semelhança do homem de raça ou

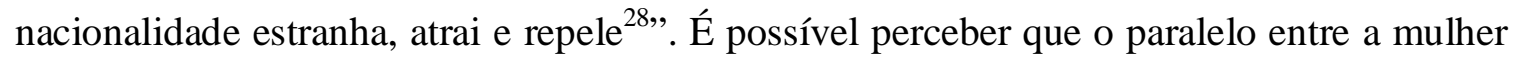
e o estrangeiro parte do suposto que os dois representam alteridades. O que os diferencia é o fato de a mulher representar um "outro" inscrito no corpo da nação e o estrangeiro representar a alteridade fora dos limites da nação. De tal maneira Paz concebe a mulher como o "outro" que em determinado momento de seu texto, pergunta: "Cifra viva da estranheza do universo e de sua radical heterogeneidade, a mulher: oculta a morte ou a vida? Em que pensa? Por acaso pensa? Sente, de fato? É igual a nós? ${ }^{29, "}$.

\footnotetext{
${ }^{26}$ Idem, pp. 66-7.

${ }^{27}$ Ver Octavio Paz, O Labirinto da Solidão e Post-Scriptum, Rio de Janeiro: Paz e Terra, 1976.

${ }^{28}$ Idem, p. 60.

${ }^{29}$ Idem, p. 63.
} 
Paz demonstra que existem diversas "mães da pátria" mexicana, que ocupam lugares distintos no imaginário. Existe a "Mãe Virgem", simbolizada pela Guadalupe, a "Mãe Chingada", aquela que produz filhos a partir da violação e a Malinche, a que se entrega voluntariamente ao conquistador:

"O símbolo da entrega é doña Malinche, a amante de Cortez. É verdade que ela se entrega voluntariamente ao Conquistador, mas este, mal ela deixa de ser-lhe útil, a esquece. Doña Malinche se converteu em uma figura que representa as índias, fascinadas, violadas ou seduzidas pelos espanhóis. E do mesmo modo que a criança não perdoa à sua mãe para ir em busca de seu pai, o povo mexicano não perdoa à Malinche a sua traição. Ela encarna o aberto, o chingado, em relação aos nossos índios, estóicos, impassíveis, fechados (...) Daí o êxito do adjetivo depreciativo "malinchista” (...). Os malinchistas são os partidários de que o México se abra ao exterior: os verdadeiros filhos da Malinche, que é a Chingada em pessoa ${ }^{30,}$.

Aliada à noção de antipatriotismo dirigido às compatriotas que se unem a europeus ou norte-americanos, o imaginário construído em torno da inferioridade racial também compõe a cultura colonial e pós-colonial em toda a América ${ }^{31}$. Em muitos casos, a naturalização da desigualdade material entre senhores e escravos foi legitimada por uma desigualdade racial e por direitos diferenciados. Dessa forma, a prerrogativa da hierarquia racial ocorre tanto na República Dominicana como no Brasil, que a despeito das grandes narrativas de mestiçagem e mezcla, não apenas concebem os negros como alteridades no interior da nação como também policiam suas condutas.

\footnotetext{
${ }^{30}$ Idem, pp. 80-1.

31 Ver Giralda Seyferth, "Construindo a nação: hierarquias raciais e o papel do racismo na política de imigração e colonização”, In: MAIO, Marcos Chor (org.). Raça, ciência e sociedade, Rio de Janeiro: FIOCRUZ, 1996
} 
Stolcke retrata os pressupostos da Sanção Pragmática, uma espécie de código civil colonial, criado em 1775, com o objetivo de "evitar os matrimônios desiguais frente "os tristes efeitos e gravíssimos prejuízos que ocasionam os casamentos que costumam acontecer entre pessoas de esfera e condição muito desiguais ${ }^{32 \%}$.

“(...) a aplicação da Pragmática nas colônias enfrentava consideráveis dificuldades. Os setores sociais de posses limitadas tinham pouco a perder, contraindo matrimônio contra a vontade familiar. Ainda que esses matrimônios não fossem freqüentes, havia os que desejavam casar-se por amor ou para remediar um deslize sexual pré-conjugal, apesar de possíveis diferenças sociais. Além disso, o problema crucial era constituído pelos matrimônios inter-raciais. Preconceitos sócio-raciais e razões de Estado nem sempre conseguiam vencer paixões que não eram sequer sempre juvenis, nem imperativos eclesiásticos morais (...)

As autoridades coloniais manifestam constante preocupação pela preservação da limpeza de sangue. (...) um decreto de 1810 [exige] dos nobres e de pessoas de conhecida limpeza de sangue e maiores de idade que quisessem contrair matrimônios com negros, mulatos e outras castas uma licença das autoridades civis coloniais. Isso equivale não só a uma potencial proibição de matrimônio inter-raciais, mas também torna evidente que o matrimônio é uma questão de Estado.

Assim, o que está em jogo já não são só interesses familiares, mas a estabilidade da ordem social. Nas colônias isso quer dizer: hierarquia racial. Cuba, uma das últimas colônias espanholas, em franco auge econômico como produtora de açúcar por uma massa escrava em rápido aumento, transforma-se em terreno privilegiado dessa legislação matrimonial ${ }^{33 \text { ", }}$

\footnotetext{
${ }^{32}$ Ver Verena Stolcke, op. cit., p. 69.

${ }^{33}$ Idem, p. 70.
} 
Assim, a existência de um passado colonial que regulamentava a conduta de escravos e senhores e, sobretudo, interpretava a mistura como algo maléfico faz com que um conjunto de sentimentos contraditórios seja acionado para definir os casamentos internacionais e inter-raciais. Enquanto na grande narrativa nacional, tanto brasileira como dominicana, a mistura é louvada e legitimada, a existência de casais formados por mulheres não-brancas e europeus problematiza esta perspectiva, pois evocam no imaginário a hierarquia racial que, assim definida, indica a existência de alteridades raciais no interior da nação. Dado que todas as minhas interlocutoras, mesmo as que se declararam brancas, se percebiam como não brancas frente a seus parceiros estrangeiros, é possível concluir que estas mulheres estão situadas no entre-lugar da nação. Talvez, exatamente por isso, tenham optado por desafiar suas posições identitárias raciais e nacionais unindo-se a um estrangeiro loiro de olhos azuis. A reação imediata de reprovação medida através dos olhares de condenação assume, em muitos contextos, um convite para a perda da nacionalidade (ou "perda do companheirismo profundo e horizontal"), pois estas mulheres agem como se ignorassem a hierarquia interna de suas nações. Tais relatos estão fortemente presentes nas experiências das brasileiras Roberta e Flávia e de quase todas as interlocutoras dominicanas. A partir da linha de raciocínio sugerida por Stolcke de que o relacionamento inter-racial desafia a ordem social estabelecida ${ }^{34}$, as relações das cariocas e dominicanas não-brancas com um europeu sintetizam, por conseguinte, uma das mais altas afrontas à nação.

Para finalizar, gostaria de concluir este artigo fazendo referência às reflexões de Frantz Fanon, que indicam que tanto o branco é escravo de sua brancura como o negro de sua negritude e problematiza, com isso, a disposição das dicotomias constitutivas do mundo

\footnotetext{
${ }^{34}$ Ver Verena Stolcke, op. cit., p. 71.
} 
colonial quando indaga se o negro é ridículo ou manifesta resistência perante o poder? E o branco, está comodamente instalado no topo da hierarquia?

Fanon resume esta relação a partir do que Bhabha chamou de entre-lugar, pois tanto a rejeição como a vontade de ser negro ou branco são desejos pertinentes tanto no imaginário europeu como no antilhano, embora a ênfase do autor esteja no imaginário dos negros. Ao analisar o livro de memórias de Mayotte Capécia Je suis Martiniquaise, Fanon ilustra esta posição, pois Mayotte ama, acima de tudo, a brancura de seu amante. O romance tem como cenário a Martinica e retrata o amor de Mayotte a Andre, um sargento da Marinha Francesa. De acordo com Fanon,

\footnotetext{
“Mayotte aime un Blanc dont elle accepte tout. C'est le seigneur. Elle ne réclame rien, n'exige rien, sinon un peau de blancheur dans sa vie. Et quand, se posant la question de savoir s'il est beau ou laid, l'amoureuse dira: “ Tout ce que je sais, c'est qu'il avait les yeux bleus, les cheveux blons, le teint pâle, et que je l'aimais" - il est facile de voir, en remettant les termes à leur place, qu'on obtient à peu pès ceci: “Je l'aimais parce qu'il avait les yeux bleus, les cheveux blonds et le teint pâle.” Et nous qui sommes Antillais, mous ne le savons que trop: le nègre craint les yeux bleus, répète-t-on là-bas ${ }^{35}$ ",
}

Fanon entende que a existência de "Mayotes Capécias" é um desdobramento lógico do universo colonial. No entanto, Fanon também aponta para a interdição do amor entre mulheres negras e homens brancos, posto que brancos e negros constituem duas entidades em absoluta contradição e em luta permanente em torno da dinâmica tensa que envolve o desejo e a rejeição. Tais contradições impossibilitariam a plenitude do amor, pois brancos e negros representam um dilema existencial de primeira ordem.

\footnotetext{
${ }^{35}$ Ver Frantz Fanon. Peau Noire, Masques Blancs, Paris: Editions du Seuil, 1952, p. 36.
} 


\begin{abstract}
"L'amour est interdit aux Mayotte Capécia de tous les pays. Car l'autre ne doit pas me permettre de réaliser des phantasmes infantiles: il doit au contraire m'aider à les dépasser. Nous retrouvons dans l'enfance de Mayotte Capécia un certain nombre de traits qui illustrent la ligne d'orientation de l'auteur. Et chaque fois qu'il y aura un mouvement, un ébranlement, ce sera toujours en rapport direct avec ce but. Il semble en effet que pour elle le Blanc et le Noir représentent les deux pôles d'un monde, pôles en lutte perpétuelle: véritable conception manichéiste du monde; le mot est jeté, il fualt s'en souvenir - Blanc ou Noir, telle est la question ${ }^{36,}$.
\end{abstract}

O desejo de Mayotte de transitar entre seu lugar fixo de mulher negra martiniquense e o de André, homem branco francês é recorrente nas trajetórias de quase todas as interlocutoras que se relacionam com europeus. Além disso, seu desejo de cruzar a fronteira que separava seu bairro dos locais de classe alta de Fort-de-France, é semelhante à postura das cariocas.

O resguardo da virgindade, a espera por un rubio, a recusa aos homens dominicanos, a aversão à sexualidade dos homens negros, também indicam que o desejo por europeus loiros de olhos azuis abarca a subversão de suas posições de alteridades no interior da nação e suas inscrições como mulheres a partir do entre-lugar da nação dominicana. Esta subversão encontra, no Brasil e na República Dominicana, tanto um campo de permissão como um de reprovação. Minhas interlocutoras percorrem todos esses caminhos. E, será a partir do trânsito entre esses universos dicotômicos que será possível compreender os dilemas apresentados nestas relações.

\footnotetext{
${ }^{36}$ Idem, p. 38.
} 


\section{Referências Bibliográficas}

AGIER, Michel. "Etnopolítica - a dinâmica do espaço afro-baiano" In: Estudos AfroAsiáticos, n. ${ }^{\circ} 22,1992$.

ANDERSON, Benedict. Nação e Consciência Nacional, São Paulo: Ática, 1989 (traduzido do original em inglês Imagined Communities. Reflections on the Origin and Spread of Nationalism. Londres: Verso, 1983).

ANDÚJAR, Carlos P. Identidad Cultural y Religiosidad Popular, Santo Domingo, República Dominicana: Editora Cole, 1999. 2001.

. De Cultura y Sociedad. Santo Domingo, República Dominicana: Editora Manatí,

ANTHIAS, Floya e YUVAL-DAVIS, Nira. Racialized Boundaries: race, nation, gender, colour and class and the anti-racist struggle, Londres e Nova York: Routledge, 1992.

ARAÚJO, Ricardo Benzaquén de. Guerra e Paz. Casa Grande \& Senzala e a obra de Gilberto Freyre, Rio de Janeiro: Editora 34, 1994.

ARREDONDO Y PICHARDO, Gaspar. "Memoria de mi salida de la Isla de Santo Domingo el 28 de abril de 1805". (Ed.) Emilio Rodríguez Demorizi. Invasiones Haitianas de 1801, 1805 y 1822. Ciudad Trujillo: Academia Dominicana de la Historia, 1955.

APPIAH, Kwame Anthony. Na casa de meu pai: a África na filosofia da cultura, Rio 
de Janeiro: Contraponto, 1997.

BALAGUER, Joaquín. La Isla al Revés, Haití y el Destino Dominicano, Santo Domingo, República Dominicana: Edit. Librería Dominicano, 1984.

BAUD, Michael et alli. Etnicidad como Estrategia en América Latina y el Caribe, Quito, Equador: Ediciones Abya-Yala, 1996.

BHABHA, Homi. O Local da Cultura, Belo Horizonte: Ed. UFMG, 2001.

CAMBEIRA, Alan Belén. "Historical and Cultural Connections: La République d'Haiti and La República Dominicana" In: The Dominican Republic in Historical and Cultural Perspective, New York: M. E. Sharpe Publishers, 1997.

CAPÉCIA, Mayotte. Je Suis Martiniquaise. Paris: Corréa, 1948; Prix France-Antilles, 1949.

CASTORIADIS, Cornelius. A Instituição Imaginária da Sociedade. São Paulo: Paz e Terra, 1986.

CHANLATTE, Antonio. “Al Gobierno Francés y a Todos los Amigos de la Soberanía Nacional y del Orden". Santo Domingo, 20 de Prairial, Año VIII (9 de junho de 1800) (Ed.) Emilio Rodríguez Demorizi, La Era de Francia em Santo Domingo. Ciudad Trujillo: Academia Dominicana de la Historia, 1955.

DANTICAT, Edwidge. Cosecha de Huesos, Barcelona: Lúmen, 2000.

DEL MONTE Y TEJADA, Antonio. Historia de Santo Domingo, Ciudad Trujillo, República Dominicana: Impresora Dominicana, 1953.

DELAFOSSE, Lemonier. Segunda Campaña de Santo Domingo. Guerra DomínicoFrancesa de 1808, Santiago: Editorial El Diario, 1946.

DESPRADEL I BATISTA, Guido. Raíces de Nuestro Espíritu: un Ensayo. Santo Domingo, República Dominicana: Renovación, 1971.

DEWOLIS, Moyiz. "Kouman ou ka al Beladè?” In: Bon Nouvèl, n. 365, Port au Prince, Haiti: Etaj Enprimri Lafalanj, 2000.

DIEDERICH, Bernard e AL BURT. Papa Doc et Les Tontons Macoutes. Port-au-Prince, Haití: Imprimerie Henri Deschamps, 1986.

DURAND, Osvald. "Choucoune" In Poésis Choisies, Port-au-Prince: Imprimerie des Antilles, 1964. 
DURKHEIM, Émile. As Regras do Método Sociológico. São Paulo: Martins, 1975.

ENLOE, Cynthia. "Bananas, Beaches and Bases: Making Feminist Sense of International Politics" In: YUVAL-DAVIS, Nira e ANTHIAS, Floya (orgs.), Woman-Nation-State, Londres: Routledge, 1989.

FANON, Frantz. Peau Noire, Masques Blancs, Paris: Editions du Seuil, 1952; Pele Negra, Máscaras Brancas. Rio de Janeiro: Fator, 1983.

FIRMIN, Anténor. De l'égalité des races humaines, Port-au-Prince: Editions Panorama, 1963 (originalmente publicado em 1885).

GARCÍA, José Gabriel. Compendio de la Historia de Santo Domingo. Santo Domingo: Imprenta de García Hermanos, 1892.

GUILLAUMIN, Colette. Racism, Sexism, Power and Ideology, Londres: Routledge, 1995.

HENRY, Paget. Caliban's Reason: Introducing Afro-Caribbean Philosophy, Londres/Nova Iorque, Routledge, 2000

HOBSBAWN, Eric. Nações e Nacionalismos desde 1780, Rio de Janeiro: Paz e Terra, 1991.

. "Etnia e Nacionalismo na Europa de Hoje" In: BALAKRISHNAN, Gopal (org.)

Um Mapa da Questão Nacional, Rio de Janeiro: Contraponto, 2000.

HOFFMAN, Leon-François. "Slavery and Race in Haitian Letters" In: Caribbean Review, 9 (2): 28-32, 1980.

KLÈZINE, Jènelis. "Yon Koutje sou Savanèt" In: Bon Nouvèl, no. 358, Port au Prince, Haiti: Etaj Enprimri Lafalanj, 1999.

KNIGHT, Franklin W. Race, Ethnicity, and Class: Forging the Plural Society in Latin America and the Caribbean, The Seventeenth Charles Edmondson Historical Lectures, Baylor University, Waco, Texas, March 27 and 28, 1995.

KRISTEVA, Julia. Strangers to Ourselves, New York: Columbia University Press, 1991.

MANIGAT, Mirlande. "Los Derechos Humanos en la Constitución Haitiana de 1987" In: TEJEDA, Eddy (Ed.) El Derecho a una Vida Digna, Santo Domingo, República Dominicana: FLACSO, 2002.

MARRERO ARISTY, Ramón. República Dominicana: origen y destino del pueblo cristiano más antiguo de la América, Ciudad Trujillo, República Dominicana: Ed. Del Caribe, 1957. 
MAUSS, Marcel. Coleção Grandes Cientistas Sociais. Roberto Cardoso de Oliveira (editor). São Paulo: Ática, 1979.

MURRAY, Gerald F. "Bon-Dieu e os ritos de passagem no Haiti rural: determinantes estruturais da teologia e dos rituais pós-coloniais" In: Estudos Afro-Asiáticos, no. 19, 1990.

NICHOLLS, David. From Dessalines To Duvalier: Race, Colour and National Independence in Haiti, New Brunwick, NJ: Rutgers Univ. Press, 2000.

PARKER, Andrew; RUSSO, Mary; SOMMER, Doris e YAEGER, Patrícia (orgs.) Nationalisms \& Sexualities, Nova Iorque: Routledge, 1992.

PAZ, Octavio. O Labirinto da Solidão e Post-Scriptum. Rio de Janeiro: Paz e Terra, 1976.

PIERRE-CHARLES, Gérard. El Caribe Contemporáneo, México: Siglo XXI Editores, 1981.

PRICE-MARS, Jean. Así Habló el Tío, Santo Domingo, República Dominicana: Ed, Manatí, 2000 (tradução do original Ainsi parla l’oncle publicado em 1928).

RODRÍGUEZ DEMORIZI, Emilio (Ed.) Cesión de Santo Domingo a Francia. Ciudad Trujillo, República Dominicana: Archivo General de la Nación, 1958.

Invasiones Haitianas de 1801, 1805 y 1822. Ciudad Trujillo, República Dominicana: Academia Dominicana de la Historia, 1955.

. La Era de Francia en Santo Domingo. Ciudad Trujillo, República Dominicana: Academia Dominicana de la Historia, 1955.

ROSA-RIBEIRO, Fernando. 'História e Narrativas de Etnicidade e Construção da Nação nos Países Baixos e sua Diáspora'. Boletim do Museu Paraense Emílio Goeldi, Antropologia, 15(1), 1999b, 125-161.

. O Encontro (Pós-Colonial): "Raça”, História e Território no Brasil, áfrica do Sul e Caribe (mimeo). 
SMITH, M.G. Pluralism, Politics and Ideology in the Creole Caribbean, Vera Rubin Caribbean Series Number One, New York: Research Institute for the Study of Man, 1991.

SILIÉ, Rubén. "Población y Esclavitud en Santo Domingo, en el Siglo XVIII", Revista Investigación y Ciencia, Universidad APEC, Año 1, No. 1, 1986.

. "Esclavege et Prejuge de Coleur en Republique Dominicaine", Revue FrancoHaitienne, Conjonction no. 147, 1980.

INOA, Orlando e ANTONIN, Arnold (ed.) La República Dominicana y Haití frente al futuro, Santo Domingo, República Dominicana: Ediciones FLACSO-Programa República Dominicana, 1998.

, SEGURA, Carlos e DORE CABRAL, Carlos (editores), La Nueva Inmigración Haitiana, Santo Domingo, República Dominicana: Ediciones FLACSO - Programa República Dominicana, 2002.

STASIULIS, Daiva e YUVAL-DAVIS, Nira (orgs.). Unsettling Settler Societies. Articulations of Gender, Race, Ethnicityand Class. Londres/Thousand Oaks/Nova Deli: Sage Publications, 1995.

STOLCKE, Verena. "Sexo está para gênero assim como raça para etnicidade?", Caderno de Estudos Afro-Asiáticos, n. 20, 1991.

"Mulheres invadidas: sexo, raça e classe na formação da sociedade colonial", Caderno de Estudos Afro-Asiáticos, n. 21, 1991.

STUDER, Brigitte. "Citizenship as Contingent National Belonging: Married Women and Foreigners in Twentieth-Century Switzerland", Gender \& History, Vol. 13 No. 3. Novembro 2001, pp. 622-654.

TAUSSIG, Michael. Mimesis and Alterirty: a particular history of the senses. New York, London: Routledge, 1993.

TROUILLOT, Michel-Rolph. "The Caribbean Region: An open frontier in anthropological theory”, Annual Review of Anthropology 1992, 21:19-42.

WALBY, Sylvia. “A Mulher e a Nação” In Balakrishnan, Gopal (org.) Um Mapa da Questão Nacional, Rio de Janeiro: Contraponto, 2000. 
PDF created with pdfFactory Pro trial version www.pdffactory.com 